\title{
Carpal Tunnel Syndrome as an Occupational Disease
}

\author{
Klaus Giersiepen, Michael Spallek
}

\section{SUMMARY}

Background: Carpal tunnel syndrome (CTS) has been listed since 2003 in the European Union's list of occupational diseases. In 2001, it took sixth place in frequency among all occupational diseases recognized in the European Union. It was not listed as an occupational disease in Germany until July 2009, when the medical expert advisory panel of the German Federal Ministry of Labour and Social Affairs issued an evaluative paper supporting its listing.

Methods: We selectively reviewed the literature on the potential causation of CTS by occupational activities.

Results: Repetitive manual work tasks involving flexion and extension at the wrist, forceful grip with the hand, and/or vibrations of the hand and arm, such as are induced (for example) by hand-held vibrating tools, can damage the median nerve and cause CTS. A combination of these exposures has been found to raise the risk of CTS with a more than additive effect. Harmful exposures arise in a wide variety of occupations; in judging whether a particular case of CTS is of occupational origin, the physician has to consider the actual manual tasks performed by the patient, rather than merely the job title. Working at a computer keyboard seems not to raise the risk of CTS.

Conclusion: The causation of CTS by occupational activities, either alone or in combination with other factors, has been well documented by epidemiological data and is pathophysiologically plausible. In Germany, a physician who diagnoses carpal tunnel syndrome in an employee with a relevant, damaging occupational exposure is required to report the case to the German Social Accident Insurance.

- Cite this as:

Giersiepen K, Spallek M: Carpal tunnel syndrome as an occupational disease. Dtsch Arztebl Int 2011; 108(14): 238-42. D0I: 10.3238/arztebl.2011.0238
Zentrum für Sozialpolitik, Gesundheitsökonomie, Gesundheitspolitik und Versorgungsforschung, Universität Bremen: Dr. med. Giersiepen

Volkswagen Aktiengesellschaft, Wolfsburg, Gesundheitswesen: Dr. med. Spallek arpal tunnel syndrome (CTS) results from compression, usually chronic, of the median nerve at the wrist. CTS is one of the readily diagnosed compression neuropathies and, in Germany, fulfils the pathophysiological criteria for the official Occupational Disease No. 2106 ("Neural Deficit Caused by Compression"). In the most recent revision of the recognized occupational diseases in 2001, however, the regulating authority excluded CTS - together with diseases of the spine arising from the intervertebral discs (1). CTS has been listed as occupational disease number 506.45 in the European Union's register of occupational diseases since 2003, and was recognized as an occupational disease in 9 of the then 12 members of the EU as early as 2001. At that time CTS was ranked sixth among the recognized occupational diseases (2). In Scandinavia, as well as in countries outside Europe, compensation for diseases wholly or partly of occupational origin was introduced many years ago $(3,4)$. In 2009, the German Federal Ministry of Labour and Social Affairs published a scientific research paper by its medical expert advisory panel supporting the listing of CTS as an occupational disease (5).

In this article we discuss sections of the scientific arguments for inclusion of CTS in the German list of occupational diseases with particular regard to the causal connection with occupational activities as described in the literature. Furthermore, we explain in which cases an occupational disease report has to be submitted to the responsible insurance body (German Social Accident Insurance) and what can be expected in the way of compensation.

\section{Clinical symptoms and diagnosis}

The clinical symptoms of CTS include irritative symptoms such as nocturnal paresthesias, spontaneous pains characterized by proximal radiation, the "shaking sign" (disappearance of the symptoms after vigorous flapping of the hands), neural deficits, and positive results on the standard provocation tests. These include the Tinel sign, triggered by percussion of the carpal tunnel; the patient reports pain resembling an electric sensation along the course of the median nerve right into the fingertips (Figure 1). In the Phalen test, paresthesias in the area supplied by the median nerve are caused by holding the hands against each other in full palmar flexion; parasthesias begin after 30 to $120 \mathrm{~s}$ in this position (Figure 2). However, none of these 


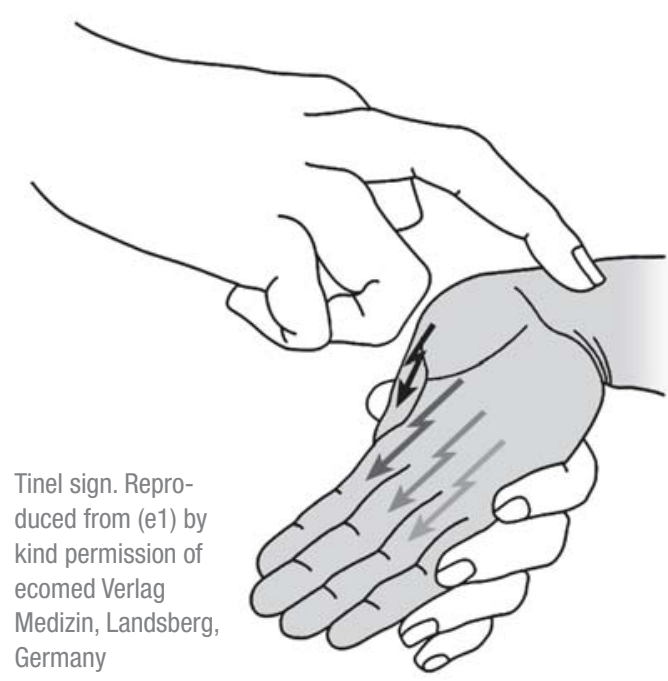

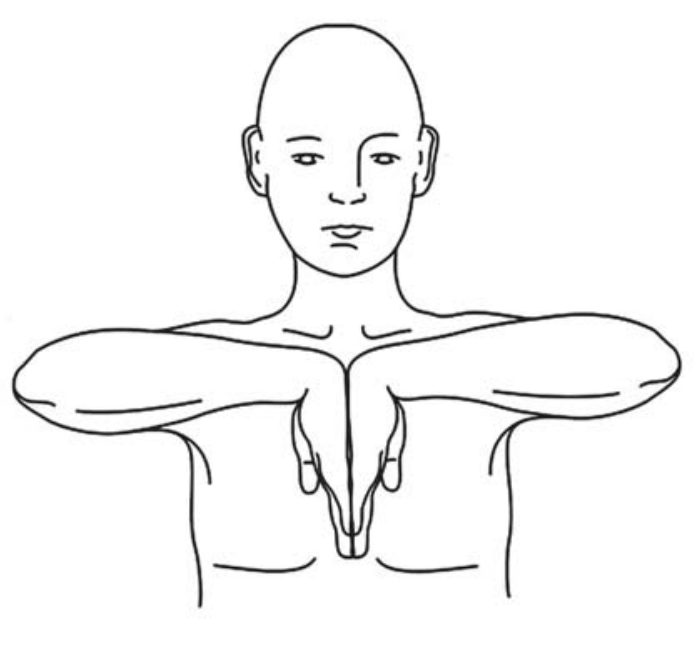

Phalen test. Reproduced from (e1) by kind permission of ecomed Verlag Medizin, Landsberg, Germany clinical characteristics alone suffices for the diagnosis of CTS. Typically there are often motor and sensory deficits in the area supplied by the median nerve. One essential reproducible and objectifiable parameter is a pathological change in motor and sensory conduction velocity $(6, \mathrm{e} 2)$.

CTS is the commonest non-traumatic peripheral nerve lesion. Women are affected 3 to 10 times more often than men, and not infrequently the CTS is bilateral (7).

\section{Prevalence: the registration criteria are decisive}

The criteria used to define CTS play a considerable part in establishing the prevalence. The literature shows that when only subjective complaints are recorded, the prevalence is much higher than when clinical and neurophysiological criteria are employed. In a study from the Netherlands, the prevalence in 25- to 74-yearold female members of the general population was $9.2 \%$. Some $5.8 \%$ of the women had symptoms and positive findings on neurological testing but had not had CTS diagnosed previously. The overall prevalence in 25- to 74-year-old men was much lower at $0.6 \%(7)$.

In a report from southern Sweden, Atroshi et al. confirmed the distinctly higher prevalence in women. A survey in which 25- to 74-year-old women were asked about symptoms yielded a rate of $17.3 \%$. Clinical examination of the same collective showed a prevalence of only $4.6 \%$. Based on electrophysiological investigation alone, $5.2 \%$ of all women had CTS. If both a positive clinical examination result and a pathological electrophysiology finding were required for diagnosis of CTS, 3.0\% of all women were affected. For men in southern Sweden the CTS prevalence rates were 10.4\% (survey), 2.8\% (examination), (4.3\% (electrophysiology), and $2.1 \%$ (examination and electrophysiology) (8).

With the same rates of CTS in Germany, between 818000 and 4.7 million women and from 570000 to 2.8 million men aged 25 to 74 years would be affected.

Investigations in companies have shown, for example, rates of $24 \%$ to $43 \%$ among employees working on conveyor belts $(9,10)$.

\section{Number of new cases per year (incidence)}

Decompression of the carpal tunnel is among the most frequently performed surgical interventions in Germany. Every year around 300000 operations are carried out, about $90 \%$ of them as day surgery (11). For the general population in the USA, Nordstrom et al. reported 35 new cases per 10000 person-years, i.e., in a given year 35 of every 10000 healthy people were affected for the first time by CTS (12). In Canada 9 CTS operations per 10000 person-years were recorded, while in Bremen (Germany) there were 10 CTS operations per 10000 person-years in men aged 21 to 64 years and 24 CTS operations per 10000 person-years for women aged 21 to 64 years. In some cases both hands were treated $(13,14)$.

In Siena (Italy) the annual incidence was 13.9 per 10000 person-years for men and 50.6 per 10000 person-years for women. The peak incidence in women was in the age group 50 to 59 years, while in men there were two peaks, one at 50 to 59 and the other at 70 to 79 years (15). The highest CTS operation rates in the general population were recorded in Ontario (Canada) in 1988: 37 per 10000 women aged 50 to $<55$ years, and 24 per 10000 men aged 75 to $<80$ years (16). 
BOX 1

\section{Risk factors}

- Repetitive manual tasks with flexion and extension of the hand at the wrist, and/or

- Forceful gripping with the hand, and/or

- Hand-arm vibration, e.g., from use of hand-held machinery such as power saws and stone drillers, that leads to an increase in volume, and thus to raised pressure, in the carpal tunnel.

Those at risk include workers on conveyor belts, meat packers, poultry workers, gardeners, musicians, farmers, mechanics, factory workers, construction workers, forestry workers who use hand-held vibrating tools, supermarket checkout workers who lift and move the goods purchased, masseurs, and upholsterers $(18-20)$.

\section{BOX 2}

\section{Differential diagnosis (6)}

Common differential diagnoses

- Cervical radiculopathy of $\mathrm{C} 6$ and $\mathrm{C7}$

- Polyneuropathy

\section{Rare differential diagnoses}

- Lesions or other compression syndromes such as pronator syndrome, thoracic outlet syndrome, or scalenus syndrome

- Non-neurogenic diseases or disorders of other origin such as lower arm compartment syndrome, polymyalgia, Raynaud syndrome, or borreliosis.

FIGURE 3

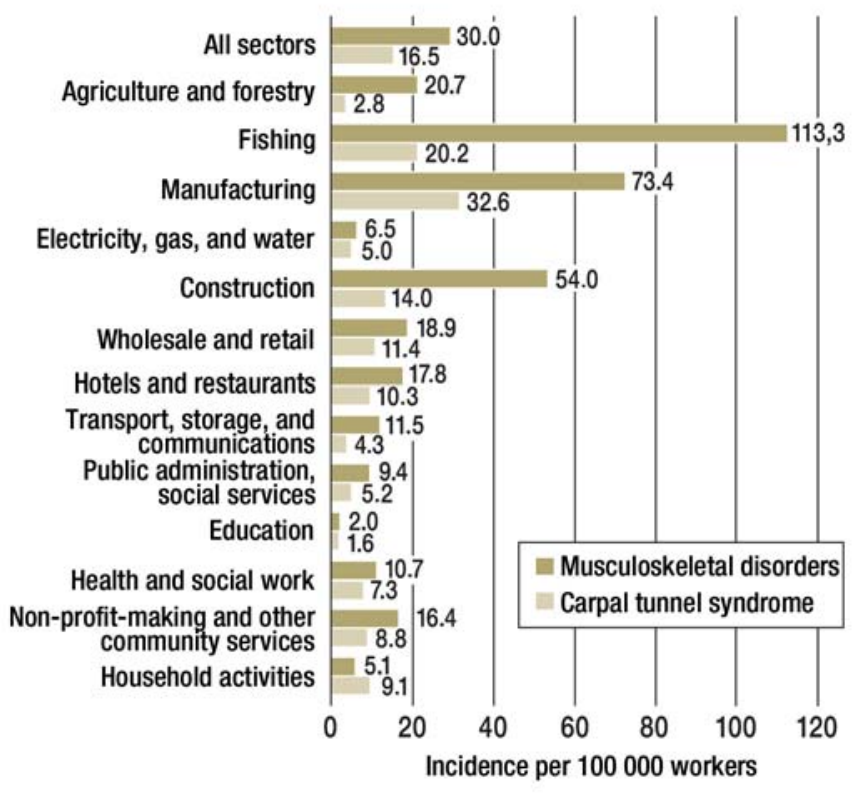

Carpal tunnel syndrome in various occupations (adapted from [e8])

\section{Differential diagnostic considerations}

Because of the wide distribution of CTS in the general population, investigation of a possible work-related cause must include not only painstaking and unambiguous neurological diagnostic testing but also close monitoring of the above-mentioned parameters and serious consideration of other possible medical and psychosocial reasons for the symptoms (Boxes 1 and 2). The treatment of CTS falls outside the scope of this study but is covered in the guidelines of the Association of the Scientific Medical Societies in Germany (6).

The higher rate of CTS in women is due partly to hormonal factors, either of natural origin or from contraceptives, with a resulting tendency towards edema. CTS that occurs during pregnancy generally resolves spontaneously post partum. The risk of CTS rises steeply after the menopause. Furthermore, women are more frequently employed in occupations where there is a risk of CTS, and household tasks can entail similar exposure. It is therefore not correct to attribute the higher risk of CTS in women solely to hormonal differences between the sexes (17).

\section{High-risk tasks and occupations}

There is sufficient pathophysiological and epidemiological evidence for a causal connection to be assumed between manual tasks in various occupations and the occurrence of CTS (18-20) (Box 1).

A feature common to these tasks is hand movements that are liable to lead to an increase in the volume of tissue in the carpal tunnel and thus to an increase in pressure on the median nerve. Such tasks may form part of the work of people in many different occupational groups (Figure 3). In assessing the probability of a causal link in an individual case, one needs to look at the actual tasks performed, not just the job title. Studies have demonstrated that combinations of work-related factors may result in a more than additive increase in risk for CTS. In particular, it can be assumed that working with hand-held vibrating tools involves strong gripping with the finger flexors and thus forced postures of the fingers and wrist, so that several components of exposure are present simultaneously $(18,19)$. A recent review indicated, for example, that CTS may be attributed to work-related factors in people whose occupations involve average demands of $>4 \mathrm{~kg}$ on hand strength or repetitive tasks with cycle times $<10 \mathrm{sec}-$ onds, or similar repetitive tasks in more than half of the cycle periods (20).

There is considerable discrepancy in the results with regard to working with a computer keyboard and mouse, due to heterogeneous diagnostic criteria, lack of comparability between study designs, and a large number of individual and psychosocial factors (21, e3-e5). To date, systematic and other reviews have not shown any increase in risk $(19,20, \mathrm{e} 6, \mathrm{e} 7)$.

\section{Latency time}

Different latency times before the occurrence of CTS are reported in the literature, but the great majority of 
publications conclude that brief exposure times suffice (22). Gorsche et al., for example, found an annual incidence of 11 cases per 100 person-years in a meatpacking plant (23). According to Chiang et al., the risk in the Taiwanese fish-processing industry was highest for exposure times of less than 12 months (24). A causal connection is plausible in patients who are diagnosed with CTS several months or even a few years after exposure. Moreover, CTS occurs at a younger age in patients with work-related causality than in the general population $(18,22)$.

\section{Reporting CTS as an occupational disease}

A report should be submitted to the responsible insurance body (German Social Accident Insurance) in cases where the symptoms persist for a number of months in association with repetitive manual tasks involving the hand, e.g., forceful gripping, or where there is longterm use of handheld vibrating machinery such as power saws and stone drillers.

According to current knowledge, an occupational cause is more likely in men than in women; this is also true in younger age groups. Onset of CTS before the menopause tends to point to an occupational pathogenesis in women.

CTS should be confirmed by neurological investigation of both wrists (median nerve), with exclusion of the differential diagnoses (Box 2). Further, a lesion of the ulnar nerve should be excluded.

Involvement of occupational factors in the causation of CTS has been documented in many reviews $(13,14$, 18-20, 22, 25). Problems in assessing the association with occupational stresses can be envisaged if various tasks are involved in which the causal factors mentioned in the scientific substantiation occur only briefly, seldom, or require only little effort. Delineation from a defined occupational disease is also often difficult in cases where two or more conditions are found simultaneously in the same limb; a hairdresser, for instance, may have epicondylitis, CTS, and possibly also tendovaginitis.

This was recognized by the medical expert advisory panel of the German Federal Ministry of Labour and Social Affairs with the publication of the scientific substantiation, with the consequence that such assessment problems will be the subject of further studies.

\section{Reduction in earning capacity and the compensation that can be expected}

German accident insurance law classes a complete lesion of the median nerve, e.g., in an accident at work, as a reduction in earning capacity of $25 \%$, in rare cases up to a maximum of $30 \%$. Owing to the favorable treatment options, the vast majority of cases of CTS lead not to a complete or persisting lesion of the median nerve, but only to low-grade sensorimotor deficit or irritation. For this reason, financial compensation can be anticipated only if another occupational disease is present or if the patient is already receiving a benefit payment according to the relevant paragraph of the German Social Code (§ 56 I 2 SGB VII) following a work accident.
Independent of the degree of reduction in earning capacity, however, the costs of medical care for any disease recognized as an occupational disorder are assumed by the accident insurer and may be reimbursed to the statutory health insurance provider (recognition without benefit payment). This shifting of the costs will lead to increased efforts by the German Social Accident Insurance and employers to improve ergonomic and organizational conditions in the workplace in such a way as to prevent the occurrence of carpal tunnel syndrome.

\section{Conflict of interest statement}

The authors declare that no conflict of interest exists.

Manuscript received on 28 December 2009, revised version accepted on 14 April 2010

Translated from the original German by David Roseveare.

\section{REFERENCES}

1. Deutsche Gesellschaft für Arbeitsmedizin und Umweltmedizin: Berufskrankheitenverordnung. www.dgaum.de/index.php/recht/be rufskrankheiten-verordnung/merkblaetter/190-merkblatt2106drucknerven

2. Karjalainen A, Niederlaender E: Occupational diseases in Europe in 2001. European Communities: Statistics in focus. 15/2004 http://epp.eurostat.ec.europa.eu/cache/ITY_OFFPUB/KSNK-04-015/EN/KS-NK-04-015-EN.PDF

3. Gorsche RG, Wiley JP, Brant R, Renger RF, Sasyniuk TM, Burke N: Comparison of outcomes of untreated carpal tunnel syndrome and asymptomatic controls in meat packers. Occup Med (Lond) 2002; 52: 491-6.

4. Bylund SH, Burström L, Knutsson A: A descriptive study of women injured by hand-arm vibration. Ann Occup Hyg 2002; 46: 299-307.

5. Bundesministerium für Arbeit und Sozialordnung: Wissenschaftliche Begründung für die Berufskrankheit „Druckschädigung des Nervus medianus im Carpaltunnel. Gemeinsames Ministerialblatt 2009; 27 : 573-81.

6. Arbeitsgemeinschaft der wissenschaftlichen medizinischen Fachgesellschaften: Leitlinie: Diagnostik und Therapie des Karpaltunnelsyndroms. Version 11/2006 www.uni-duesseldorf.de/AWMF/I/005-003m.htm

7. de Krom MCTFM, Kester ADN, Knipschild PG: Carpal tunnel syndrome: prevalence in the general population. J Clin Epidemiol 1992; 45: 373-6.

\section{KEY MESSAGES}

- As early as 2001, carpal tunnel syndrome (CTS) was ranked sixth among the recognized occupational diseases in the EU.

- In Germany, recognition of CTS as an occupational disease became possible in 2009.

- Detrimental effects can be expected to result from activities that involve repetitive movements of the hand with flexion and extension at the wrist, tasks featuring forceful gripping with the hand, and exposure to hand-arm vibration leading to increased pressure in the carpal tunnel. Combinations of these factors raise the risk of CTS.

- An official occupational disease report should be submitted when the diagnosis of CTS has been confirmed and the patient's work has involved exposure to these detrimental factors for the major part of his/her shift over a period of months.

- To date no increase in risk has been demonstrated for office work in general or use of a computer keyboard in particular. 
8. Atroshi I, Gummesson C, Johnsson R, Ornstein E, Ranstam J, Rosen I: Prevalence of carpal tunnel syndrome in a general population. JAMA 1999; 282: 153-8.

9. Werner RA, Franzblau A, Gell N, Hartigan AG, Ebersole M, Armstrong TJ: Incidence of carpal tunnel syndrome among automobile assembly workers and assessment of risk factors. J Occup Environ Med 2005; 47: 1044-50.

10. Bonfiglioli R, Mattioli S, Spagnolo MR, Violante FS: Course of symptoms and median nerve conduction values in workers performing repetitive jobs at risk for carpal tunnel syndrome. Occup Med 2006; 56: 115-21.

11. Bundesgeschäftsstelle Qualitätssicherung: Karpaltunnelsyndrom. 2007. www.bqs-qualitaetsindikatoren.de/2007/ergebnisse/leis tungsbereiche/karpaltunnelsyndrom/index_html

12. Nordstrom, DL, DeStefano F, Vierkant RA, Layde PM: Risk factors for carpal tunnel syndrome in a general population. Occup Environ Med 1997; 54: 734-40.

13. Rossignol M, Stock S, Patry L, Armstrong B: Carpal tunnel syndrome: what is attributable to work? The Montreal study. Occup Environ Med 1997; 54: 519-23.

14. Giersiepen K, Eberle E, Pohlabeln H: Populationsbezogene Fall-Kontrollstudie stützt Zusammenhang zwischen beruflichen Einflüssen und dem Carpaltunnel-Syndrom. In: A.W.Rettenmeier, C. Feldhaus, (eds.): Dokumentationsband der 39. Jahrestagung der Deutschen Gesellschaft für Arbeitsmedizin und Umweltmedizin e.V., 1999; 403-07.

15. Mondelli M, Giannini F, Giacchi M: Carpal tunnel syndrome incidence in a general population. Neurology 2002; 58: 289-94.

16. Liss GM, Armstrong C, Kusiak RA, Gailitis MM: Use of provincial health insurance plan billing data to estimate carpal tunnel syndrome morbidity and surgery rates. Am J Ind Med 1992; 22: 395-409.

17. McDiarmid M, Oliver M, Ruser J, Gucer P: Male and female rate differences in carpal tunnel syndrome injuries: personal attributes or job tasks? Environ Res 2000; 83: 23-32.

18. Bernard BP, (ed.): Musculoskeletal disorders and workplace factors. A critical review of epidemiologic evidence for work-related muscu- loskeletal disorders of the neck, upper extremity, and low back. US Department of Health and Human Services, National Institute for Occupational Safety and Health 1997. http://www.cdc.gov/niosh/ docs/97-141/

19. Palmer KT, Harris EC, Coggon D: Carpal tunnel syndrome and its relation to occupation: a systematic literature review. Occup Med 2007; 57: 57-66.

20. van Rijn RM, Huisstede BMA, Koes BW, Burdorf A: Associations between work-related factors and the carpal tunnel syndrome - a systematic review. Scand J Work Environ Health 2009; 35: 19-35.

21. Andersen JH, Thomsen JF, Overgaard E, et al.: Computer use and carpal tunnel syndrome: a 1-year follow-up study. JAMA 2003; 2963-9.

22. Masear VR, Hayes JM, Hyde AG: An industrial cause of carpal tunnel syndrome. J Hand Surg [Am] 1986; 11: 222-7.

23. Gorsche RG, Wiley JP, Renger RF, Brant RF, Gemer TY, Sasyniuk TM: Prevalence and incidence of carpal tunnel syndrome in a meat packing plant. Occup Med 1999; 56: 417-22.

24. Chiang HC, Ying-Chi KO, et al.: Prevalence of shoulder and upperlimb disorders among workers in the fish-processing industry. Scand J Work Environ Health 1993; 19: 126-31.

25. Armstrong T, Dale AM, Franzblau A, Evanoff BA: Risk factors for carpal tunnel syndrome and median neuropathy in a working population. J Occup Environ Med 2008; 50: 1355-64.

\section{Corresponding author \\ Dr. med. Michael Spallek \\ Volkswagen Aktiengesellschaft \\ Gesundheitswesen \\ Postfach 1599 \\ 38436 Wolfsburg, Germany \\ michael.spallek@volkswagen.de}

(2) For eReferences please refer to: www.aerzteblatt-international.de/ref1411 


\section{REVIEW ARTICLE}

\section{Carpal Tunnel Syndrome as an Occupational Disease}

Klaus Giersiepen, Michael Spallek

\section{eReferences}

e1. Spallek M, Kuhn W: Funktionsorientierte körperliche Untersuchungssystematik. Die fokus Methode zur Beurteilung des Bewegungsapparates in der Arbeits- und Allgemeinmedizin. Heidelberg, München, Landsberg: Ecomed Verlag Medizin 2009.

e2. Boocock MG, Collier J, McNair PJ, Simmonds M, Larmer PJ, Armstrong B: A framework for the classification and diagnosis of work related upper extremity conditions: systematic review. J Semarthrit 2009; 38: 296-311.

e3. Al-Hashem FH, Khali ME: The effect of long-term use of computer mouse devices on median nerve entrapment. Neurosciences 2008; 13: 131-5.

e4. Aydeniz A, Gürsoy S: Upper extremity musculoskeletal disorders among computer users. Türk J Med Sci 2008; 38: 235-8.

e5. Tornqvist EW, Hagberg M, Hagman M, Risberg EH, Toomingas A: The influence of working conditions and individual factors on the incidence of neck and upper limb symptoms among professional computer users. Int Arch Occup Environ Health 2009; 82: 689-702.

e6. Friedebold A, Scutaru C, Mache S, Quarcoo D, Groneberg DA, Spallek M: Das Karpaltunnelsyndrom - eine klinische Übersicht. Zbl Arbeitsmed 2009; 59: 242-51.

e7. Thomsen JF, Gerr F, Atroshi I: Carpal tunnel syndrome and the use of computer mouse and keyboard: a systematic review. BMC Musculoskelet Disord 2008; 9: 134.

e8. Schneider E, Irastorza X (European Agency for Safety and Heath ot work (EU-OSHA)): Work related muskuloskeletal disorders in the EU-fact and figures 2010. http: osha.europa.eu/en/ publications/reports/TER009009ENC/view 